\title{
Recent advances in nature conservation in the Lao PDR
}

\author{
Klaus Berkmüller, Tom Evans, Rob Timmins and Vene Vongphet
}

The Lao People's Democratic Republic (PDR) has long been a white spot on maps depicting national parks and similar protected areas. This changed dramatically with the official declaration in October 1993 of 18 protected areas covering over 10 per cent of the country's land surface. Among the countries of South East Asia Lao PDR now ranks among those with the highest proportion of land under legal protection. The political climate seems favourable and additional areas may still be added. System planning and, increasingly now, the management of declared areas has been carried out by the Protected Areas and Wildlife Division of the Centre for Protected Areas and Watershed Management (PAWM), Forest Department, with funding by the Swedish International Development Agency (SIDA) and technical support from IUCN-The World Conservation Union. Some of the most vulnerable species, such as the Javan rhinoceros Rhinoceros sondaicus, may already be extirpated, but most species and ecosystems have good prospects of survival if management of the reserves and some wider conservation initiatives can be implemented.

\section{Background}

Land-locked Lao PDR covers 236,800 sq km and has a mostly rural population of some 4.5 million. With an annual per capita income below \$US200, Lao PDR is one of the poorest countries in the world. In the highlands some 60 per cent of the population experience chronic rice shortages for about 3 months per year. Eighty-five per cent of the population are engaged in agriculture and 90 per cent lack access to basic health services. The country has been a one-party socialist state since the 1975 revolution, but has permitted private enterprise since 1988 and is gradually adopting a market-orientated economy. Foreign investment and limited tourism are encouraged.

Lao PDR lies mostly east of the Mekong river. It remains comparatively well forested (47 per cent in 1991; Manivong and Sandewall, 1992), in stark contrast to its neighbours Thailand, Vietnam and China. It is also free from the armed conflict that still devastates parts of Myanmar and Cambodia.
Of the main geographical regions of the country, the plains of the Mekong and its tributaries have been mostly converted to agriculture or otherwise deforested. Few major wetlands remain. Extensive forests still cover the hill ranges and some of the valleys in central and southern Laos. The mountainous north has suffered most from deforestation, mainly as a result of shifting cultivation. In this region significant tracts of little-disturbed forest are found in only four localities. Elsewhere in the northern highlands, vegetation cover consists of a mosaic of shifting cultivation fallow. This generally reverts to forest, although vast areas have already been degraded to bamboo, scrub or grass. Nevertheless, there is reason to anticipate that this little-studied country might be a refuge for vulnerable species, including many Indo-Chinese endemics such as the recently discovered saola Pseudoryx nghetinhensis.

Biogeographically, Lao PDR lies within the Indo-Chinese Subregion of the Indo-Malayan Realm (MacKinnon and MacKinnon, 1986). 
Three subunits converge here: the Central Indochina tropical lowland plains, the Northern Indochina hilly subtropical sector, and the Annam Trung Son mountain chain (Figure 1). Just under half of Laos's land area falls within the tropical lowland plains. Somewhat less than one-third falls into the hilly subtropical sector and the remainder is within the Annam range.

\section{The protected areas system}

Systematic planning for a protected area system started in 1988. No formally protected areas existed at the time other than several unmanaged forest reserves established under the colonial administration. The national implementing agency was then the Wildlife Branch of the Department of Wildlife and

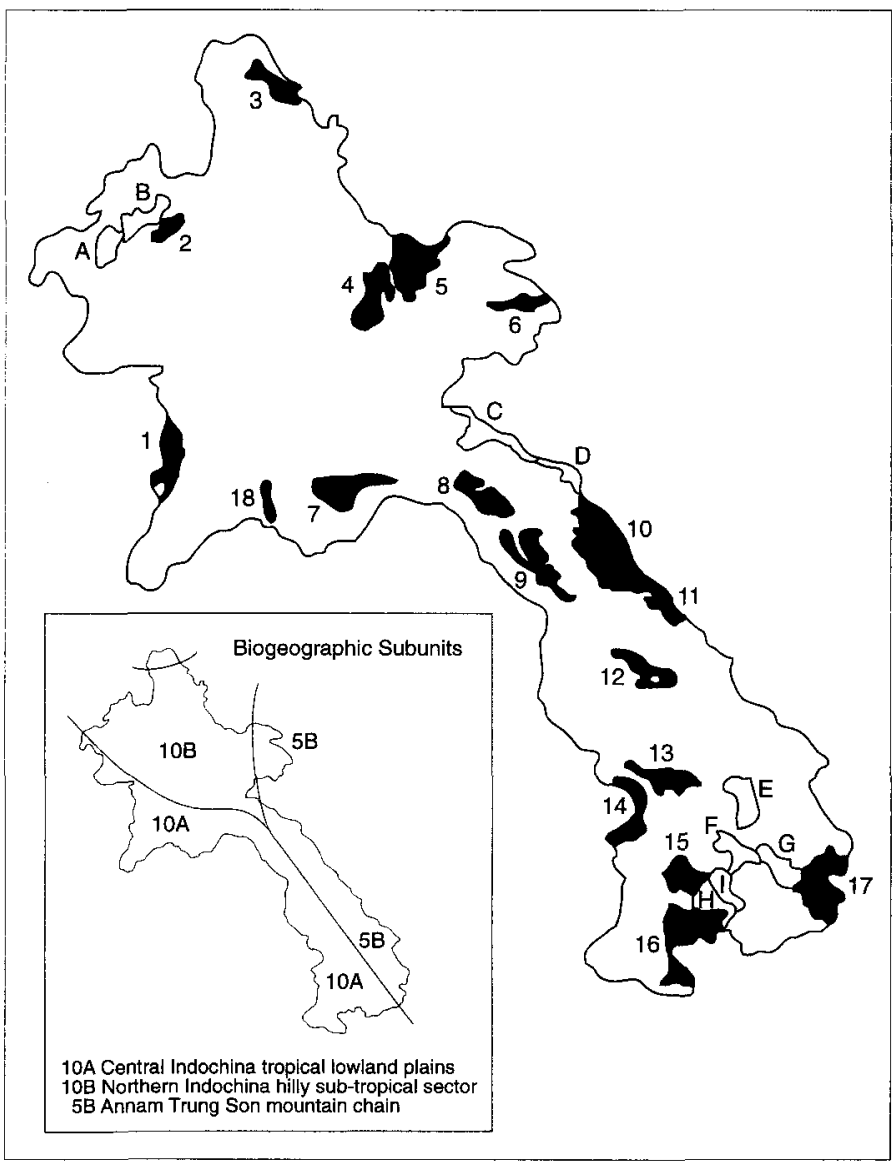

Subunit $10 \mathrm{~A}$

1 Nam Poui

7 Phou Khao Khoay

8 Nam Kading

9 Khammouane Lime.

12 Phou Xang $\mathrm{He}$

13 Xe Bang Nouan

14 Phou Xiang Thong

15 Dong Hua Sao

16 Xe Pian

G Phou Kathong Proposed (1860 sq km)

H Xe Khampho A Nam Kan

I Bolovens Southwest B Nam Ha (West)
Figure 1. Protected areas and biogeographical subunits in Lao PDR.

Subunit 5B

6 Nam Xam

10 Nakai-Nam Theun

11 Hin Namnu

17 Dong Ampham

Proposed (2460 sq km)

C Nam Chuan

D Nakai-Nam Theun extension 
Fisheries (DWFC). This has since been reorganized and re-named the Centre for Protected Areas and Watershed Management (PAWM) of the Department of Forestry. Funding was provided under the LaoSwedish Forestry Cooperation Programme (LSFCP) and technical support by IUCN.

The planning process entailed the compilation of information on sites previously recommended by various sources or judged as promising on the basis of satellite imagery. The suitability of an area for protection was determined during reconnaissance surveys. A few broad criteria were used: (a) presence of key species as judged from village interviews; (b) habitat condition and degree of disturbance as judged by direct observation and indirect evidence; and (c) minimum size of 500 $\mathrm{sq} \mathrm{km}$. The selection process is detailed in Salter and Phanthavong (1989), Salter et al. (1991) and Berkmüller et al. (1993).

The objective was to establish representative cover (at least 10 per cent of the original extent) for each major vegetation type in each of the three main biogeographic subunits (Figure 1) in large, self-contained reserves. By mid1993, 17 high-priority sites covering 24,400 sq $\mathrm{km}$ had been recommended for declaration as National Biodiversity Conservation Areas (NBCAs). Eighteen areas, including the 17 recommended areas, were officially declared by decree issued from the Prime Minister's Office (PM 164) on 29 October 1993. The one area Phou Phanang) that had not been recommended has limited value for biodiversity conservation and was selected by the government partly for historical reasons.

The Lao protected areas thus meet one major international criterion for national parks and comparable designations in that they are protected under the highest political authority. Extractive commercial uses are prohibited. Subsistence use is permitted outside designated core areas. In the short- to medium-term Lao protected areas will be de facto multiple-use areas with the important proviso that they are reserved for subsistence by local users. It is anticipated that by year 3 to 5 of management a sizeable core zone that meets the criteria of a national park or nature reserve will have been established.

Between October 1993 and March 1995 eight new areas and extensions were identified totaling $8730 \mathrm{sq} \mathrm{km}$. A few areas remain under investigation, but over all, the options for establishing large protected areas with intact forest cover have been identified.

\section{Coverage by NBCAs achieved to date}

The formally declared NBCAs are shown in Figure 1. National and regional coverage in terms of land area is summarized in Figure 2. Overall coverage stands at 10.6 per cent of the land area. Among South East Asian countries only Thailand, with $\mathbf{1 2 . 6}$ per cent, has a higher percentage of land area under protection. Coverage remains well below 10 per cent in the Northern Highlands subunit but recently recommended additions may increase coverage from the present 6 to 8 per cent.

Calculations of coverage of different forest types remain tentative because vegetation mapping is still incomplete and false classifications are known to have occurred on the existing maps. Of the major vegetation types, evergreen forest seems under-represented, particularly in the Northern Highlands subunit but also in the Mekong Plains subunit, at levels probably well below 10 per cent of original cover of this forest type.

\section{Future protected area system development}

System design has by necessity been biased towards large forest areas and thus under-represents some habitats. Wetlands are poorly covered and some of the many types of 'evergreen forest' may not be covered adequately. A partial inventory of wetlands was carried out in 1993 (Claridge, 1993a, b) but has not yet been acted on. The major high-altitude ( $>2000$ $\mathrm{m})$ zone in the Annamite subunit is represented in the newly recommended, but not yet declared, Nam Chuan area.

Figures on forest type representation in the 


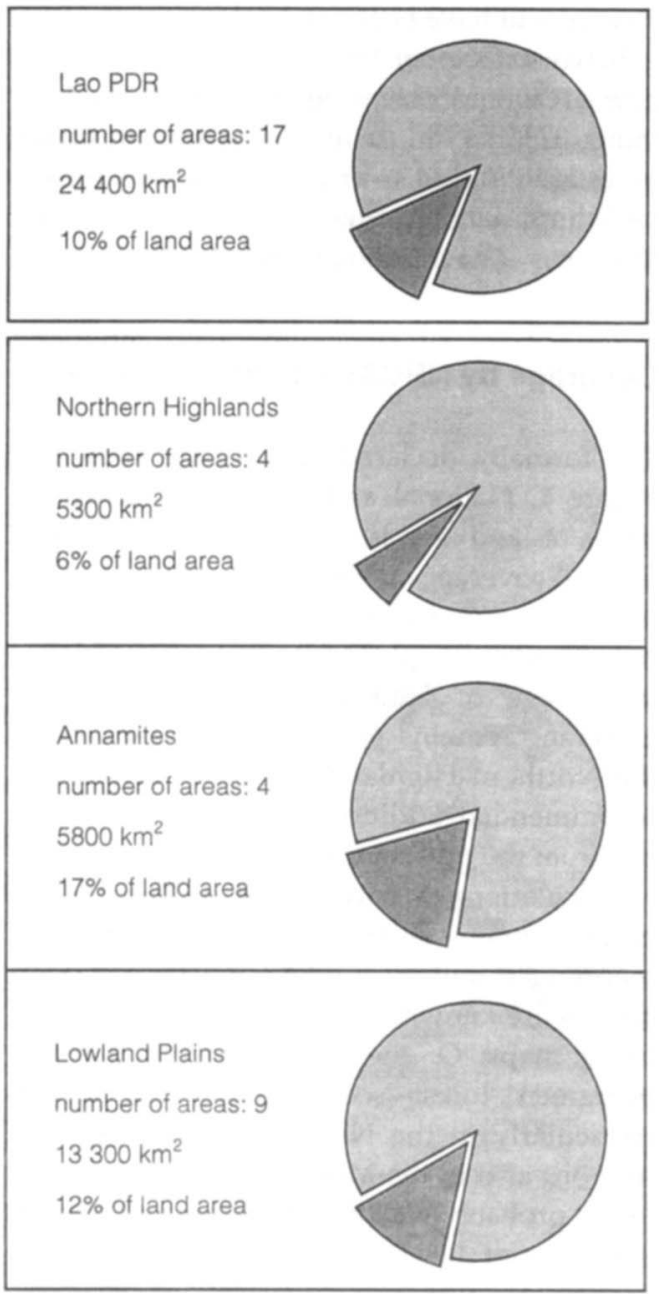

Figure 2. Protected area coverage.

upcoming mid-1995 Status Report will all be based on vegetation cover maps drawn from 1989-91 satellite imagery and will alleviate some of the uncertainty of coverage, particularly for the Northern Highlands. Further research and improved vegetation cover maps will yield new information about the detailed distribution of forest types.

The search for and selection of large forest tracts will be completed by mid-1995. Thereafter emphasis will shift towards the identification of smaller areas and habitat links between existing reserves. Recommendations of new areas and extensions, which would link Xe Pian, Dong Hua
Sao and Dong Ampham NBCAs via parts of the Bolovens plateau and Sekong river plains into one very large interconnected complex of protected areas, already exist. Smaller blocks of lowland evergreen forest and riverine habitats may still be identified for protection in view of their species diversity and increasing rarity throughout South East Asia.

\section{Other initiatives}

Some of the country's ecosystems, particularly the major rivers, cannot be protected adequately in reserves alone, and the capacity of provinces and districts must be developed to enable them to identify and protect such areas. Operating costs of protected areas are kept as low as possible but are by no means assured to be provided after external support ends. No clear and systematic procedures exist for the screening of major development projects and the information base upon which such decisions are made is generally inadequate. The existing prohibitions of wildlife trade and regulations of trade are difficult to enforce.

To overcome the problems mentioned above a number of initiatives are either planned or ongoing.

- Drafting a national conservation strategy with technical assistance from IUCN

- Completion of the wetlands inventory (Claridge, 1993a,b) and selection of wetland protected areas

- Applied research and project development focusing on the sustainable use of minor forest products

- Lao Government accession to CITES (Nash and Broad, 1993)

- Support for community-level conservation measures by the fishing communities of the lower Mekong to protect their traditional livelihoods (Baird and Mounsouphom, 1993a,b), funded by The Asia Foundation and The Earth Island Institute.

- Development of eco-tourism with private sector participation in and around protected areas.

- Analysis of hydropower development projects and their impact on protected areas. 
- Establishment of a protected areas trust fund

- After completion of preliminary surveys, application to obtain international recognition for selected areas under the World Heritage Convention.

\section{Management strategy}

The predominantly rural population in Lao PDR is widely dispersed and all wildlands are subject to subsistence foraging and hunting. Lao protected areas, therefore, have to combine features of nature reserves/national parks with those of managed resource areas. The main objective of protected area management is to reduce and eventually eliminate extractive uses in core areas that are critical for biodiversity conservation and the survival of key species, while maintaining or increasing the productivity of the remaining area as a subsistence resource.

A management strategy has been developed with the aim of eventually reaching land-use agreements with regular users of protected area resources (Figure 3). The strategy is described in detail in the 1993 status report (Berkmüller et al., 1993). It consists of a series of stages. In stage 1 (pre-management activities) preliminary boundaries and basic protection measures are cleared with provincial government. Shortly before management implementation is about to begin a draft management plan is discussed in meetings (stage 2) with representatives of local government down to district level. These are followed by subdistrict and village level meetings. The meetings aims are: to obtain local approval of the respective protected area, to inform local people and authorities of its goals and objectives, and to discuss practical land use implications. A few readily acceptable rules are introduced at this stage. During the subsequent information stage (stage 3 ), wildlife surveys and land-use surveys are conducted to provide the information needed for conflict resolution. Wildlife and botanical surveys draw attention to critical subsections of the protected area. Land-use surveys reveal

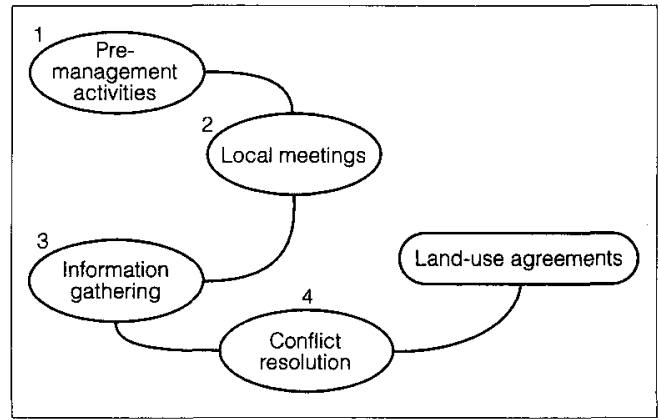

Figure 3. Management steps.

the extent of people's dependency on protected-area resources and land-use patterns. An analysis of data from both types of survey allows the determination of the nature and seriousness of conflicts, their location and the stake-holders involved (stage 4). Land-use agreements, which focus on discrete conflicts, are then negotiated.

Five areas were under active management as of March 1995. Four of these are still at stage 3 , while one area has reached the conflict resolution stage. It takes considerable time and requires frequent visits before inexperienced staff are sufficiently familiar with routine management tasks, such as work planning, information gathering and reporting. Evaluations of management implementation in all areas suggest that an inadequate first-hand knowledge of the field constitutes the major obstacle to problem solving. Low skill levels, limited motivation and insufficient institutional capacity pose greater constraints to management implementation than funding.

\section{The status of wildlife in the Lao PDR}

Historical information is sparse or non-existent for most taxonomic groups. The majority of records date back to the French colonial period, which ended in the late 1940s. The only significant studies of wildlife in the following four decades were those of Jean Deuve (summarized in Deuve, 1972) and Chazee (1990) on mammals. No new ornithological information was published between 1949 and 1992. 
After 1988, travel restrictions for foreigners were relaxed. Since then a few highly focused surveys have been conducted: of kouprey Bos sauvelii and other wild cattle (Salter et al., 1990; Cox et al., 1991, 1992); of fish and Irrawaddy River dolphins Orcaella brevirostris in the lower Mekong (Baird, 1991, 1992; Baird and Mounsouphom, 1993a, b; Roberts, 1993; I. Baird, unpubl. data) and of cross-border wildlife trade with Thailand (Srikosamatara $e t$ al., 1992; Martin, 1992).

During reconnaissance surveys, presence/ absence for key species data were systematically recorded during structured village interviews around candidate protected areas. The results of 355 interviews are held on file at head office. They were summarized, along with other recent information available at that time, in Salter (1993).

The first area-focused faunal surveys started in 1992-93 when a team from the UK surveyed the birds, mammals and habitats of $\mathrm{Xe}$ Pian NBCA (Duckworth et al., 1993a), Phou Xang He NBCA (Duckworth et al., 1993b) and Dong Hua Sao NBCA (Timmins et al., 1993). In 1994 the Wildlife Conservation Society, formerly the New York Zoological Society, embarked on a long-term programme of surveys and staff-training, which started with faunal surveys in Nakai-Nam Theun NBCA, Xe Bang Nouan NBCA, and Phou Khao Khoay (Wildlife Conservation Society, unpubl. data). All surveys were carried out with local protected area staff and one or two staff of the Inventory and Research Section of PAWM.

Among the major findings have been the rediscovery of the giant ibis Pseudibis gigantea (Duckworth et al., 1993a), feared extinct for the last three decades, the confirmation of the presence in Laos of the newly discovered saola Pseudoryx nghetinhensis (R. J. Dobias, pers. comm. 1993, Wildlife Conservation Society, in prep.) and, most recently, the discovery of an, as yet, undescribed species of muntjac, Muntiacus sp., simultaneous with its discovery in Vietnam (Wildlife Conservation Society, in prep.). A northern extension of the Nakai-Nam Theun NBCA and the contiguous newly recommended Nam Chuan NBCA cover confirmed and suspected distribution areas of the saola.

It has been saddening to find that hunting has very severely depleted populations of many large wildlife species, including tiger Panthera tigris, gaur Bos gaurus, banteng Bos javanicus, Siamese crocodile Crocodylus siamensis, green peafowl Pavo muticus, white-shouldered ibis Pseudibis davisoni and sarus crane Grus antigone. Some species, including the Javan rhinoceros Rhinoceros sondaicus and, perhaps, the Sumatran rhinoceros Dicerorhinus sumatrensis, Eld's deer Cervus eldii, hog deer Axis porcinus and kouprey Bos sauveli probably only survive as scattered individuals, if at all. Concerted conservation action in Lao PDR over the next few years might yet halt the decline of some of these species, for which so much suitable habitat remains intact.

Among those that still occur in numerous locations of Lao PDR and/or in viable populations are such important species as Asian elephant Elephas maximus, the Indochinese gibbon Hylobates gabriellae, saola, the newly discovered muntjac, red-shanked douc langur Pygathrix nemaeus, white-winged wood duck Cairina scutulata, Siamese fireback Lophura diardi, crested argus Rheinartia ocellata and rufous-necked hornbill Aceros nipalensis. Initial indications are that most smaller species (e.g. forest passerine birds, including many regional endemics) occur in healthy numbers.

It is hoped that further surveys will locate surviving populations of poorly known Lao endemic forms such as Roosevelt's muntjac Muntiacus rooseveltorum, Laotian Francois' langur Semnopithecus francoisi laotum and sooty babbler Stachyris herberti.

\section{Conclusions}

Management implementation in the protected area system is set against a backgrourid of rapid population growth and accelerating exploration for and extraction of natural resources, most notably timber and hydropower. Commercial and largely unsustainable logging is widespread throughout the central and southern region but there are clear signs that the Lao Government is making a 
major effort to control it. Some 30 hydroelectric power projects are planned and are expected to be major sources of hard currency over the next few decades. Road communications are being upgraded, with new interior roads and overland links to China, Thailand and Vietnam. Impact assessments for these projects, if carried out at all, have tended to be highly inadequate.

Environmental safeguards, of which the protected areas system is one, are necessary to prevent the serious environmental problems that now plague neighbouring Thailand and Vietnam. There are worrying reports from the basin of the Nam Theun-Nam Kading rivers and elsewhere, which suggest that central government policy will only be gradually accepted and enforced in the provinces. However, in all fairness it should be emphasized that a good measure of political will and awareness exist to safeguard the national heritage exist at the higher levels of government. Central government control may not yet be complete in the provinces but the general trend towards improvement of environmental safeguards is encouraging for all who aspire to setting up a well-managed protected-area system. The Lao PDR still has rich resources of forest and wildlife, which could be the envy of its neighbours in years to come. It is to be hoped that the Lao Government, backed by external aid, will ensure that current positive trends to safeguard this wealth continue.

\section{Acknowledgements}

Three agencies have been instrumental in making the Lao protected area system a reality: the Centre for Protected Areas and Watershed Management (PAWM) of the Forestry Department, Ministry of Agriculture and Forestry, as the national implementing agency; the Swedish International Developmental Agency as the main donor; and the World Conservation Union-IUCN as the source of technical assistance. All the staff of PAWM, especially Bouaphanh Phanthavong and Khamphet Chanhthavong, contributed much to the success of the programme. We thank the numerous advocates of conservation in leadership positions whose efforts resulted in the formal decalaration of 18 protected areas in October 1993. The enthusiasm of Chanthaviphone Inthavong, director of PAWM, in his ongoing commitment to the programme needs special acknowledgement. We would be remiss not to mention Richard Salter, who in 1988 inititated and helped lay the solid foundations on which the system planning process has been built. Many organizations and individuals have contributed to the programme in the intervening period; special thanks must go to all those involved in the wildlife and habitat surveys, which have provided so much information on Lao's rich natural heritage. These surveys have been supported since late 1993 by the Wildlife Conservation Society. None of these surveys would have succeeded without the assistance of the Lao wildlife field team - Chainoi Sisomphone, Boonhon Sounthala, Bounsou Souan, Chamkhoun Khounboline and Somphong Souliyavong - to whom we are particularly indebted. Lastly but not least, thanks must be said to all the local people who have been of tremendous help during fieldwork, and on whom much of the success of the protected area system will depend.

\section{References}

Baird, I. 1991. Preliminary Survey of the Irrawaddy Dolphin in Lao PDR. Unpublished report for the Earth Island Institute and The Whale and Dolphin Conservation Society.

Baird, I. 1992. Second Report on the Irrawaddy Dolphin in Lao PDR. Unpublished report for the Earth Island Institute and The Whale and Dolphin Conservation Society.

Baird, I. and Mounsouphom, B. 1993a. Lao Community Fisheries and Dolphin Protection Project. Progress Report 1, January-July 1993. Unpublished report

Baird, I. and Mounsouphom, B. 1993b. Lao Community Fisheries and Dolphin Protection Project. Progress Report 2, August-December 1993. Unpublished report

Berkmüller, K., Phanthavong, B. and Vene Vongphet. 1993. Protected Areas System Planning and Management in Lao PDR Status Report to mid1993. Forest Resources Conservation Programme, Lao/Swedish Forestry Cooperation Programme, Vientiane, Lao PDR.

Chazee, L. 1990. The Mammals of Laos and the Hunting Practices. Unpublished report, Vientiane, Lao PDR.

Claridge, G. (compiler) 1993a. An Inventory of Selected Wetlands in Savannakhet and Champassak Provinces of the Lao PDR. Unpublished report to the Lao/Swedish Forestry Cooperation Programme, Vientiane, Lao PDR, May 1993.

Claridge, G. (compiler) 1993b. Interim Inventory of Wetlands of the Lao PDR. Unpublished report to 
the Lao/Swedish Forestry Cooperation Programme, Vientiane, Lao PDR, May 1993.

Cox, R., Sawathvong, S. and Louanglath, K. 1991. Survey for the Kouprey in Southern Laos. Report to the Kouprey Conservation Trust.

Cox, R., Laurie, A. and Woodford, M. 1992. The Results of Four Surveys for Kouprey Bos sauvelii in Vietnam and Lao PDR. Report for the Kouprey Conservation Trust.

Deuve, J. 1972. Les Mammiferes du Laos. Ministere de l'education nationale, Vientiane, Lao PDR.

Duckworth, J.W., Evans, T.D. and Timmins, R.J. 1993a. A wildlife and habitat survey of Xe Pian National Biodiversity Conservation Area. Forest Resources Conservation Programme, Lao/ Swedish Forestry Cooperation Programme, Vientiane, Lao PDR.

Duckworth, J.W., Timmins, R.J. and Cozza, K. 1993b. A Wildlife and Habitat Survey of Phou Xang He Proposed Protected Area. Forest Resources Conservation Programme, Lao/Swedish Forestry Cooperation Programme, Vientiane, Lao PDR.

MacKinnon, J. and MacKinnon, K. 1986. Review of the Protected Areas System of the Indo-Malayan Realm. IUCN, Gland, Switzerland and Cambridge, UK.

Manivong, K. and Sandewall, M. 1992. Forest Cover and Land Use in Lao PDR: Final Report on the Nationwide Reconnaissance Survey. LSFCP, Vientiane.

Martin, E.B. 1992. The trade and uses of wildlife products in Laos. TRAFFIC Bulletin, 13 (1), 23-28.

Nash, S. and Broad, S. 1993. Accession of Lao PDR to CITES and other Conservation Treaties. Unpublished report to the Lao-Swedish Forestry Cooperation Programme, Vientiane, Lao PDR, March 1993.

Roberts, T.R. 1993. Artisanal fisheries and fish ecology below the Great Waterfalls of the Mekong River in southern Laos. Nat. Hist. Bull. Siam Soc. 41 (1), 31-62.
Salter, R.E. (compiler) 1993. Wildlife in the Lao PDR: A Status Report. IUCN, Vientiane, Lao PDR.

Salter, R.E., Phanthavong, B., Sawathvong S., Souriyakan, Sand Louanglath, K. 1990. An Assessment of the Current Status of Kouprey and other Wild Cattle in Southern Laos. Forest Resources Conservation Programme, Lao/Swedish Forestry Cooperation Programme, Vientiane, Lao PDR.

Salter, R.E. and Phanthavong, B. 1989. Needs and Priorities for a Protected Areas System in Lao PDR. Forest Resources Conservation Programme, Lao/Swedish Forestry Cooperation Programme, Vientiane, Lao PDR.

Salter, R.E., Phanthavong, B. and Vene Vongphet. 1991. Planning and Development of a Protected Area System in Lao PDR. Status report to mid-1991. Forest Resources Conservation Programme, Lao/Swedish Forestry Cooperation Programme, Vientiane, Lao PDR.

Srikosamatara, S, Sirihodej, B. and Suteethorn, V. 1992. Wildlife trade in Lao PDR and between Lao PDR and Thailand. Nat. Hist Bull. Siam Soc. 40,147.

Timmins, R.J., Evans, T.D. and Duckworth, J.W. 1993. A Wildlife and Habitat Survey of Dong Hua Sao Proposed Protected Area. Forest Resources Conservation Programme, Lao/Swedish Forestry Cooperation Programme, Vientiane, Lao PDR.

Klaus Berkmüller, Box 4340, Vientiane, Lao PDR.

Tom Evans, 11A Yeoman Lane, Bearsted, Maidstone, Kent ME14 4BX, UK.

Rob Timmins, 25 Cradley Road, Cradley Heath, Warley, West Midlands B64 6AG, UK.

Vene Vongphet, Centre for Protected Areas and Watershed Management, Forestry Department, Box 2932, Vientiane, Lao PDR. 